Volume 5, Issue 3, October 2020, pp. 262-275

DOI: $10.23917 /$ jramathedu.v5i3.9910

p-ISSN: 2503-3697, e-ISSN: 2541-2590

\title{
The implementation of self-explanation strategy to develop understanding proof in geometry
}

\author{
Samsul Maarif*, Fitri Alyani, Trisna Roy Pradipta \\ Department of Mathematics Education, Universitas Muhammadiyah Prof. DR. HAMKA, Indonesia \\ ${ }^{*}$ Corresponding author: samsul_maarif@uhamka.ac.id
}

\begin{tabular}{l}
\hline ARTICLE INFO \\
\hline Article history: \\
Received: 15 January 2020 \\
Revised: 6 July 2020 \\
Accepted: 8 July 2020 \\
Published online: 17 July 2020 \\
Published regularly: October \\
2020
\end{tabular}

\section{ABSTRACT}

Proof is a key indicator for a student in developing mathematical maturity. However, in the process of learning proof, students have the difficulty of being able to explain the proof that has been compiled using good arguments. So we need a strategy that can put students in the process of clarifying proof better. One strategy that can explore student thought processes in explaining geometric proof is self-explanation strategy. This research aimed to analyze the ability to understand the geometric proof of prospective teacher students by implementing a selfexplanation strategy in basic geometry classes. This study used a quasiexperimental research type of nonequivalent control group design. The participants of this research were 75 students of mathematics education study programs at one private university in Semarang. This research used four

Keywords:

Self-explanation, proving geometry, understanding instrument tests of geometric proof. Before being used for research, the instruments were tested for validity and reliability using product-moment and Cronbach's alpha. Data analysis in this study used a two-way ANOVA test. The results showed that: the increased ability to understand the geometric proof of students who used self-explanation strategy was better than those who obtained direct learning; there was a significant difference between the increase of students' mathematical proof ability in a group of students with a high and moderate level of initial mathematical ability; the initial ability (high, medium, low) of mathematics did not directly influence the learning process to improve the ability to understand the geometric proof. Hence, it can be concluded that the selfexplanation strategy is effective to be used to improve the understanding of the geometric proof.

(C) 2020 Universitas Muhammadiyah Surakarta

\section{Introduction}

Geometry curriculum in mathematics education contains plane, space, analytical plane and space, and transformation geometry. Specifically, in the study of geometry, higher education curriculum places geometry as studied material up to the axiomatic system leading to formal proof. A formal proof of geometry will be formed if students are able in formulating geometry argumentation works well and write those arguments in a formal proof. These abilities are essential since students who have no ability to abstract geometry concepts and express arguments, and then automatically, they are unable to analyze a proof (Maarif, Wahyudin, Noto, Hidayat, \& Mulyono, 2018). 
Proof is a key indicator for a student in developing mathematical maturity (Otten, Gilbertson, Males, \& Clark, 2014; Maarif, Perbowo, Noto, \& Harisman, 2019). In recent years, research has been focusing more on how students can construct proofs compared to students' activities to understand a proof that will be constructed (Samper, Perry, Camargo, Sáenz-Ludlow, \& Molina, 2016; Fiallo \& Gutiérrez, 2017; Azrou \& Khelladi, 2019). This focus can be a potential cause of students' mistakes in constructing proof because they lack an understanding of the flow of proof according to the axiomatic system.

The proving process will be effective if it is carried out through understanding and explaining activity as a fundamental proving competence (Maarif, 2013; Sommerhoff \& Ufer, 2019). Understanding geometric proofs can be done through a process of reading a proof practice. After the proof is read, the student explains it again so that the student can understand the whole idea of the geometric proof. The process of explaining the proof of geometry can get students used to form logical thinking in preparing the proof of geometry ability. Therefore, it is needed as a strategy that can improve students' understanding of geometric proof. In this study, we adopted a pedagogical strategy, a self-explanation that has been proven effective in facilitating students in understanding mathematical proofs (Hodds et al., 2014; Tsitouras, Tsivilis, \& Kakali, 2014; Roy \& Chi, M.T.H 2005; Chi, De Leeuw, Chiu, \& Lavancher, 1994).

A self-explanation strategy is recommended and suggested in learning activities to construct geometry because they can help students develop their ideas based on the knowledge they have (Kumar, 2014; Tsitouras et al., 2014; Conati, 2016; Rittle-Johnson, Loehr, \& Durkin, 2017). The study by Rittle-Johnson et. al. concluded that self-explanation strategy is an effective learning technique to support procedural and conceptual transfer in various mathematical topics. Other studies revealed that self-explanation strategy contributes to students' knowledge through automatic feedback in the problem-solving process (McNamara, 2017). Conceptual and procedural knowledge becomes an important part of the student in constructing their ideas with a feedback process to be written in geometric proof.

A self-explanation strategy is a metacognitive strategy to mediate individual thoughts between internal mental models and presenting external information, forming an understanding and revising weakness of the mental model (Ainsworth \& Burcham, 2007). Self-explanation strategy in learning is useful for students' understanding of facts, concepts, principles, and procedures to correct misconceptions about the subject matter of mathematics being taught (Tekeng, 2015). Self-explanation aimed to: first, anticipate reasoning to predict the next action; second, a link between goals and actions; third, elaborate problems; fourth understand the coherence between texts, examples, and problems; fifth monitor negative understanding; and sixth, monitor positive understanding (Chi et al., 1994). A Self-explanation strategy has the following steps: comprehension monitoring, paraphrasing, inference bridging, prediction, and elaboration (Kurby et al., 2012).

To proof understanding of geometry, students are determined how far they have their initial mathematical abilities. In the learning process, there will always be differences in the students' high, medium, and low levels due to the ability of students to spread like a normal distribution (Haeruman, Rahayu, \& Ambarwati, 2017). One of the best predictors to know the mathematical ability is through previous mathematics learning of students with the process of determining high, medium, and low groups (Vilkomir \& O'Donoghue, 2009).

Research of self-explanation strategy has been extensively studied in several previous studies on self-explanation strategy (Wylie, Koedinger, \& Teruko, 2004; Al Rumayyan et al., 2018; McNamara, 2017). This research is widely applied in language and outside the fields 
of mathematics education (Nguyen, Trawiński, \& Kosala, 2015; Wylie et al., 2004; Kwon, Kumalasari, \& Howland, 2011). Even though several studies have applied self-explanation strategy in the algebra (Kumar, 2014; Tsitouras et al., 2014; Conati, 2016; Rittle-Johnson, Loehr, \& Durkin, 2017), however, the strategy has not been widely applied in learning geometry, particularly in understanding geometric proof. In this study, the researchers conducted a self-explanation strategy to develop the ability to understand the geometric proof.

Mathematical proof of students determines how far the initial mathematics ability they have. Yu et al. (2015) revealed from a group of randomly selected students will always students who have high, medium, and low abilities. These levels are due to the ability of students to spread normally. The process of determining high, medium, and low groups involves sorting the scores of previous mathematics learning outcomes (daily tests, midterms, or national examinations. This is in line with the findings of Yu et al. (2015) through their research that one of the best predictors of mathematics ability is the result of previous mathematics learning.

In addition, in the conditions of learning in the classroom, the ability of students is different, so it is necessary to adjust the learning environment. The selection of a suitable learning model is needed to bridge all students' abilities that occur in a lecture. This is expressed by Lestari (2017) that differences in students' ability are not merely innate, but also influenced by the environment. Therefore, we need to examine the interaction between self-explanation strategies and the students' initial abilities.

In learning, students are taught how to interpret a mathematical proof problem so that they can describe mathematical problems and can connect the existing geometrical concepts using theorems and definitions so that they are able to prove a geometry problem in accordance with their initial abilities. The use of reasoning is needed to determine and justify the conjecture that has been made based on understanding the geometrical concepts students have. The process of determining the conjecture in the mathematical proof is carried out by exploring the geometrical problems that will be proven, which will then be used as data to be justified in the conclusion in the form of formal evidence. By paying attention to the above, a self-explanation strategy is considered appropriate as an effort to increase the ability to understand the geometric proof. This study was designed to see the ability to understand the geometric proof of prospective teacher-students using selfexplanation strategies.

Therefore, we submitted research questions as follows: first, is the increasing of the geometric proof understanding ability of students who gain self-explanation strategy better than students who gain direct instruction learning?; second, is there a difference in understanding geometric proof in terms of the students' initial mathematical ability?; third, is there an interaction effect between learning factors and the level of initial mathematical ability to improve and achieve proof understanding ability?. This study described the selection of appropriate learning strategies to develop the ability to understand the proof of geometry so that it can help the process of developing the design of learning in lectures on geometry.

\section{Research Methods}

This study was a quasi-experimental research type of nonequivalent control group design (Sztajn, Wilson, Edgington, Myers, \& Dick, 2013). This study used a nonequivalent control group design because it desires to examine how the self-explanation strategy implemented to understand geometric proof. This research was conducted at the Mathematics Education Study Program at one of the private universities in Semarang. The number of participants was 75 students selected using the Cluster Random Sampling 
technique to determine one experimental class (applying self-explanation strategies) and one control class (direct instruction learning).

Based on the stages of learning using a self-explanation strategy that includes monitoring comprehensive, paraphrasing, bridging inference, predicting, and elaborating, then the steps of learning with a self-explanation strategy are implemented as Table 1.

\section{Table 1}

The stages of learning using self-explanation strategy

\begin{tabular}{|c|c|}
\hline Steps of Explanation Strategy & Students' Activities \\
\hline Monitoring comprehensive & $\begin{array}{l}\text { Students explore the problems presented in the proof } \\
\text { worksheet by collecting data, such as known information. } \\
\text { Students try to find out their weaknesses in knowledge by } \\
\text { asking questions to themselves: } \\
\text { - Am I understand the concept being taught? } \\
\text { - Do I not understand the concept being taught? } \\
\text { - Am I able to prove theorems being taught? } \\
\text { - Am I know theorems being taught? } \\
\text { - Do I not know five Euclid axioms? }\end{array}$ \\
\hline Paraphrasing & $\begin{array}{l}\text { If students find information that is not understood, students } \\
\text { rewrite the information in an easily understood language }\end{array}$ \\
\hline Bridging inference & $\begin{array}{l}\text { Each student makes a conclusion on the results of each thought } \\
\text { to be discussed in a group }\end{array}$ \\
\hline Predicting & $\begin{array}{l}\text { Each student provides a prediction of presented problem } \\
\text { solutions }\end{array}$ \\
\hline Elaborating & $\begin{array}{l}\text { Students discuss the prediction solution of each group member } \\
\text { to develop final conclusions from the presented problem } \\
\text { solutions. }\end{array}$ \\
\hline
\end{tabular}

The instrument used in this study was a test of the ability to understand the geometric proof. There is four ability test of understanding geometric proof. The test of understanding geometric proof uses indicators of choosing one of the two presented theorems used in proving a statement (Arnawa, Sumarno, Kartasasmita, \& Baskoro, 2007; Bieda, Ji, Drwencke, \& Picard, 2014). The following is one that was used in research by referring to indicators of choosing one of the two presented theorems that to be used in proving a statement.

Presented the following theorem:

i. If the $\mathrm{P}$ triangle and the $\mathrm{Q}$ triangle are congruent, then the ratio of the corresponding sides' lengths is equal.

ii. If two sides and an angle are enclosed in two congruent triangles, then the triangles are congruent.

Of the two theorems above, which theorem can be used to prove the following statement:

If $O$ is the intersection of the three axes of triangle $A B C$, then the distance of point 0 to the vertex of the triangle is the same.

Write down the formal proof.

To get a good measuring instrument, before it was used in a research class, an instrument test was first conducted to determine the validity and reliability level. The trial was conducted in one class consisting of 35 students. Validity analysis used productmoment with SPSS 21 software application. The validity test showed that the four items of 
the test items were able to comprehend the geometric proof in a row of $0.611 ; 0.726 ; 0.665$ and 0.467 , all of which are greater than the $r$ product moment value of 0.275 . So, it can be concluded that all test items' ability to understand the geometric proof is valid.

Based on the results of the validity test, the next step was to conduct a reliability test. The results of the decisions on each test meet the requirements for reliability testing. The reliability test was carried out using Cronbach's Alpha with the application of SPSS 21 software. The reliability test results of understanding mathematical geometric proof had $r_{\text {count }}=0.425>0.275=r_{\text {critical }}$, so it can be concluded that the mathematical proof ability test is reliable.

Data analysis was performed using statistical tests. Quantitative data that has been grouped based on the learning model and the initial students' ability level were testing using parametric statistical analysis requirements as a basis for using the type of hypothesis test. Testing the requirements carried out is a test for normality and homogeneity of data variance. Test for normality and homogeneity of data variance respectively used Shapiro-Wilk test and Levene test. The final part of the quantitative data analysis was directed to determine the effect of mutual interactions between learning models and students' initial abilities. To test the effect of these interactions, researchers planned to use two-way ANOVA test through SPSS 21 software. The reason for using twoway ANOVA test was that the effectiveness of statistical tests with several initial mathematical abilities was tested. In addition, in hypothesis testing, one of the interaction hypotheses was between the learning strategy and the initial mathematical ability factor. So, it will be more effective by using two-way ANOVA test.

Meanwhile, students' initial mathematical abilities were taken from National Examination scores at Senior High School or equivalent level grade. The National exam scores describe students' ability in mathematics because an instrument measures that the government has made nationally through a standardized process. The researcher used data of initial mathematical students' ability in Senior High School or equivalent grade with the reason that for the first time, students took lectures at the university level and describe the mathematical abilities of students in the first semester.

To deepen the meaning of the data, after analyzing statistical data, observation and interviews were with the respondents related to the application of self-explanation strategies. Those respondents represent three levels of students' ability: high (coded R1), moderate (coded R2), and low (coded R3).

\section{Results and Discussion}

The findings of the ability to understand students' geometric proof using selfexplanation strategies are presented in Table 2 . It can be seen that the ability to understand students' geometric proof who learned using a self-explanation strategy was better than those who learned using direct instruction for all initial mathematical understanding ability (high, medium, and low). If it was reviewed based on the factors that influence the increase of the understanding ability of geometric proof, it shows that the learning factor and the type of initial mathematical ability affected the development of the ability the understanding of geometric proof.

The data analysis of the ability of geometric proof through a statistical test of average difference was tested to support the description of the understanding ability of geometric proof data that has been explained above. As a prerequisite test, a normality test of the student's mathematical proof ability test was performed in the experimental and control classes. The statistical test used was Shapiro-Wilk test. Based on Shapiro-Wilk test with a significance level of $\alpha=0.05$, the Sig value of the experimental class was 0.029 , while the 
control value was Sig $=0.007$. Since both Sig values (experimental class and control class) $<0.05$, it can be concluded that the data on the ability to understand geometric proof in the experimental class was distributed normally.

Based on these results, the average difference test above was carried out using Two-Way ANOVA test presented in Table 3.

Table 2

The gain of understanding geometric proof ability based on learning factors and types of Students' initial mathematical knowledge level

\begin{tabular}{llll}
\hline $\begin{array}{c}\text { Types of Students' } \\
\text { initial mathematical } \\
\text { knowledge level }\end{array}$ & \multicolumn{1}{c}{ Learning } & Mean & SD \\
\hline High & Self-explanation (N=6) & 8.50 & 4.550 \\
& Direct Instruction (N=5) & 7.40 & 2.074 \\
Medium & Self-explanation (N=23) & 9.00 & 3.542 \\
& Direct Instruction (N=23) & 3.91 & 1.929 \\
Low & Self-explanation (N=6) & 5.67 & 2.251 \\
& Direct Instruction (N=7) & 3.14 & 2.410 \\
Total & Self-explanation (N=35) & 8.26 & 3.713 \\
& Direct Instruction (N=35) & 4.26 & 2.393 \\
\hline
\end{tabular}

Table 3

The Summary of Two-Way ANOVA in testing the increase of students' mathematical proof understanding ability based on learning factor and students' initial mathematical knowledge level

\begin{tabular}{|c|c|c|c|c|c|}
\hline Sources & $\begin{array}{c}\text { Type III Sum of } \\
\text { Squares }\end{array}$ & $\mathrm{df}$ & $\begin{array}{l}\text { Mean } \\
\text { Square }\end{array}$ & $\mathrm{F}$ & Sig. \\
\hline Learning strategy (A) & 1.056 & 1 & 1.056 & 24.190 & 0.000 \\
\hline $\begin{array}{l}\text { Type of the level of initial } \\
\text { mathematical ability (B) }\end{array}$ & 0.329 & 2 & 0.164 & 3.766 & 0.028 \\
\hline $\mathrm{A} \times \mathrm{B}$ & 0.107 & 2 & 0.054 & 1.230 & 0.299 \\
\hline
\end{tabular}

From the two-way Anova test results in Table 3, it can be seen that the Sig was 0000. Therefore, it can be concluded that there was a significant difference in the increase of geometric proof understanding between students who learned using self-explanation and students who learned using Direct Instruction at a 5\% significance level. Based on Table 3, it also obtained the value of sig for the level of initial mathematical ability of 0.028 . It can be concluded that there was a difference in increasing mathematical proof ability between students who learned using Self-Explanation strategy and students who learned using Direct Instruction based on the level of students' initial mathematical ability at 5\% significance level.

The level of initial understanding ability was tested to identify the difference between groups using Tukey HSD. The results as shown in Table 4. Based on Table 4, it can be concluded that there was a significant difference between the increase of students' mathematical proof ability in a group of students with a high and moderate level of initial mathematical ability at a significant $\alpha=0.05$. These results indicate that there was a significant difference at the initial mathematical ability level towards increasing students' understanding of geometric proof ability.

In addition, Table 3 also found that there was no significant interaction effect between Self-Explanation strategy and students' initial mathematical ability factors towards the increase of understanding geometric proof ability at a 5\% significance level ( $\operatorname{sig}=0.299$ ). This shows that mathematics's initial ability does not directly influence the learning process to improve the ability to understand the geometric proof. It means that the self-explanation strategy is very effective for all initial mathematical abilities. 
Table 4

HSDTukey test results on data of the increase of students' understanding geometric proof ability based on initial mathematical ability level

\begin{tabular}{llccccc}
\hline $\begin{array}{l}\text { (I) initial } \\
\text { mathematical } \\
\text { ability level }\end{array}$ & $\begin{array}{l}\text { (J) initial } \\
\text { mathematical } \\
\text { ability level }\end{array}$ & $\begin{array}{c}\text { Mean } \\
\text { Difference } \\
(\mathrm{I}-\mathrm{J})\end{array}$ & Std. Error & Sig. & \multicolumn{2}{c}{$\begin{array}{c}\text { 95\% Confidence } \\
\text { Interval }\end{array}$} \\
\hline High & Medium & .08117 & .062692 & .403 & -.06925 & .23160 \\
& Low & $.17304^{*}$ & .065750 & .028 & .01528 & .33080 \\
Medium & High & -.08117 & .062692 & .403 & -.23160 & .06925 \\
& Low & .09187 & .058336 & .264 & -.04810 & .23184 \\
Low & High & $-.17304^{*}$ & .065750 & .028 & -.33080 & -.01528 \\
& Medium & -.09187 & .058336 & .264 & -.23184 & .04810 \\
\hline
\end{tabular}

Based on Table 4, it can be concluded that there was a significant difference between increasing mathematical proof ability in the group of students with a high and moderate level of initial mathematical ability at significant $\alpha=0.05$. These results indicate that there was a significant difference in the level of initial mathematical ability to increase the ability to understand the geometric proof.

The results of the statistical test showed that an increase in the students' geometric proof understanding in the experimental class was better than all students who were in the control class. This result also applies to initial mathematical ability, although only in the high and medium category. These findings are also supported by the results of influence test analysis between learning factors and initial mathematical ability, which indicate that learning factors contribute positively to increased students' mathematical proof ability in the level of initial mathematical ability. This shows that self-explanation strategy has a good impact on improving students' geometric proof understanding ability in a basic geometry course. The study results are in line with the research conducted by Al Rumayyan et al.(2018), which states that students taught using self-explanation strategies can prove that deductive hypotheses from mathematical problems are better than students taught by conventional learning methods.

In the understanding stage of monitoring self-explanation strategy, students are expected to know their weaknesses in initial knowledge. Next, students determine actions to correct these weaknesses. Lecturers provide stimuli to make students aware of their own abilities. The stimulation given by the lecturer is in the form of questions on the students' worksheet. The students' worksheet was designed to meet the principles of selfexplanation. The questions were structured in order to achieve the expected evidence solution. The students feel helped by the questions in the student worksheet, which can be seen from the results of an interview between researchers $(R)$ and one of the students.

$R \quad: \quad$ In worksheets of a student, there are questions that help self-explanation in order to reach conclusions. According to R1 [mentioning the name of respondent], Do those questions help in drawing a conclusion?

R1 : Actually, this really helped me. This is due to the questions presented containing steps to reach a conclusion. So, we will be guided by those questions.

$R \quad$ : In R1 opinion [mentioning the name of respondent], in the geometry learning process, which one is better, using a learning model like this [self-explanation strategy] or conventional learning model?

$R 1 \quad$ : It is better than using this [self-explanation strategy] because we can learn by our self and learn to explain. Besides, it can improve the social relationship because we can communicate with friends. There are additional values by using this strategy (selfexplanation strategy]. 


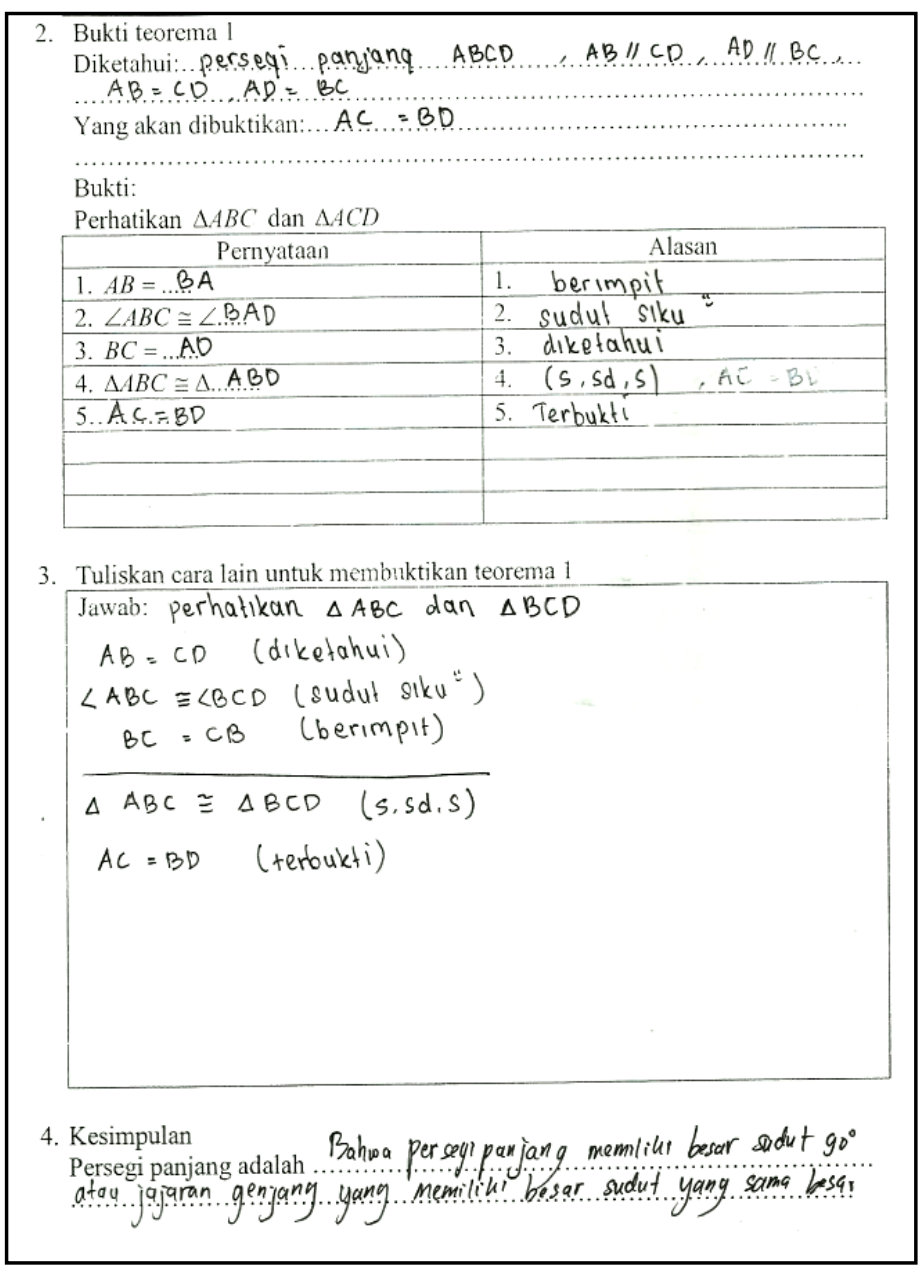

Translation of Figure 1:

2. Proof of Theorem 1

Known as a rectangle $\mathrm{ABCD}, \mathrm{AB} / / \mathrm{CD}$, $\mathrm{AD} / / \mathrm{BC}, \mathrm{AB}=\mathrm{CD}, \mathrm{AD}=\mathrm{BC}$

will be proven: $\mathrm{AC}=\mathrm{BD}$

Prove:

See $\triangle \mathrm{ABC}$ dan $\triangle \mathrm{ACD}$

\begin{tabular}{|l|l|}
\hline \multicolumn{1}{|c|}{ Statement } & \multicolumn{1}{c|}{ Reason } \\
\hline 1. $\mathrm{AB}=\mathrm{BA}$ & 1. Coincide \\
\hline 2. $\angle \mathrm{ABC}=\angle \mathrm{BAD}$ & 2.Right angle \\
\hline 3. $\mathrm{BC}=\mathrm{AD}$ & 3. Known \\
\hline 4. $\triangle \mathrm{ABC} \cong \triangle \mathrm{ABD}$ & $\begin{array}{l}\text { 4. (Side, Angle, } \\
\text { Saide) }\end{array}$ \\
\hline 5. $\mathrm{AC}=\mathrm{BD}$ & 5. Proven \\
\hline
\end{tabular}

3. Write another way to prove theorem 1 Answer: Known as $\triangle \mathrm{ABC}$ dan $\triangle \mathrm{BCD}$ $\mathrm{AB}=\mathrm{CD}($ Known) $\angle \mathrm{ABC}=\angle \mathrm{BCD}$ (Right angle)

$\mathrm{BC}=\mathrm{CB}$ (Coincide)

$\triangle \mathrm{ABC} \cong \triangle \mathrm{ABD}$ (Side, Angle, Saide) $\mathrm{AC}=\mathrm{BD}$ (Proven)

4. Conclusion

That a rectangle has an angle of $90^{\circ}$ or a parallelogram that has two equal angles.

Figure 1. The result of paraphrasing process in student worksheets

The next step of the self-explanation strategy was paraphrasing, which is the activity of stating and bringing the problem into students' own language to make it easier in deciding the problem solution that will be proven (See Figure 1). In a learning activity, students are faced with problems of proof, which then students discuss to find the solution of proof with guided questions in student worksheets. Then, students were invited to write other solution of proof that has been written by their own language. This refers to the opinion proposed by Rittle-Johnson et. al. who revealed that the repetition of written evidence was very effective in getting used to the process of proof (Rittle-Johnson et al., 2017). By updating the way the student will prove, students will get used to thinking systematically based on logic flow to gain geometric proof that will be achieved, and students will enable them to express their ideas in their own language. It can be seen that learning which used a self-explanation strategy can provide an opportunity for students to express ideas of proof in a group discussion. This refers to the opinion proposed by Boeroe (Reiss \& Renkl, 2002) that learning of proof must emphasize students' activeness in expressing ideas in constructing a proof.

One of the mathematical proof abilities is that students evaluate presented proof validity by sorting the steps of proof to obtain valid proof construction. In the selfexplanation strategy, students were assisted by worksheets that were prepared based on the strategy's steps. Students were given proof problems that were complemented by a randomly arranged proof process. Next, students in groups tried to evaluate the presented evidence validity by sorting steps of proof to obtain valid proof construction. 


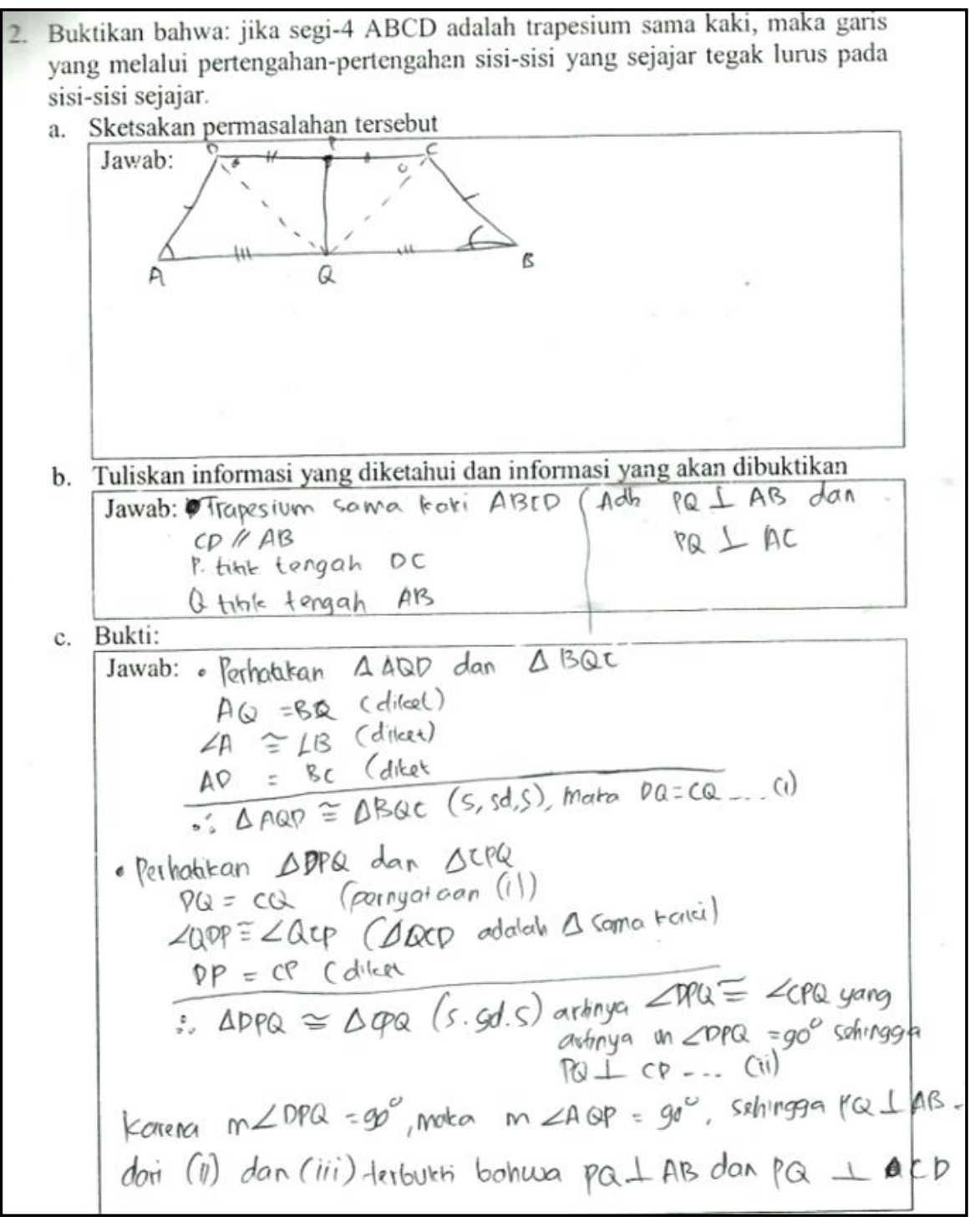

Figure 2. The answer to student's exercise in worksheets of student

Translation of Figure 2:

2. Prove that: if the rectangle ABCD is an isosceles trapezoid, then the line that passes through the midpoint of the parallel sides is perpendicular to both sides.

a. Sketch out the problem

answer:

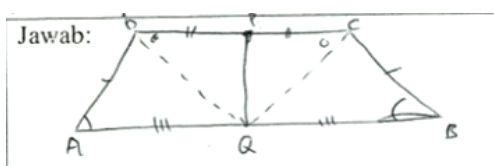

b. Write down the information that is known and information that will be proven Answer:

Known: isosceles trapezoid $\mathrm{ABCD}, \mathrm{CD} / / \mathrm{AB}, \mathrm{P}$ is midpoint $\mathrm{DC}$ and $\mathrm{Q}$ midpoint $\mathrm{AB}$

Will be proven that: $\mathrm{PQ} \perp \mathrm{AB}$ and $\mathrm{PQ} \perp \mathrm{AC}$ c. Proof:

Answer:

- $\quad$ See as $\triangle \mathrm{ABC}$ dan $\triangle \mathrm{BCD}$

$\mathrm{AQ}=\mathrm{BR}($ Known $)$

$\angle \mathrm{A}=\angle \mathrm{B}$ (Known) 


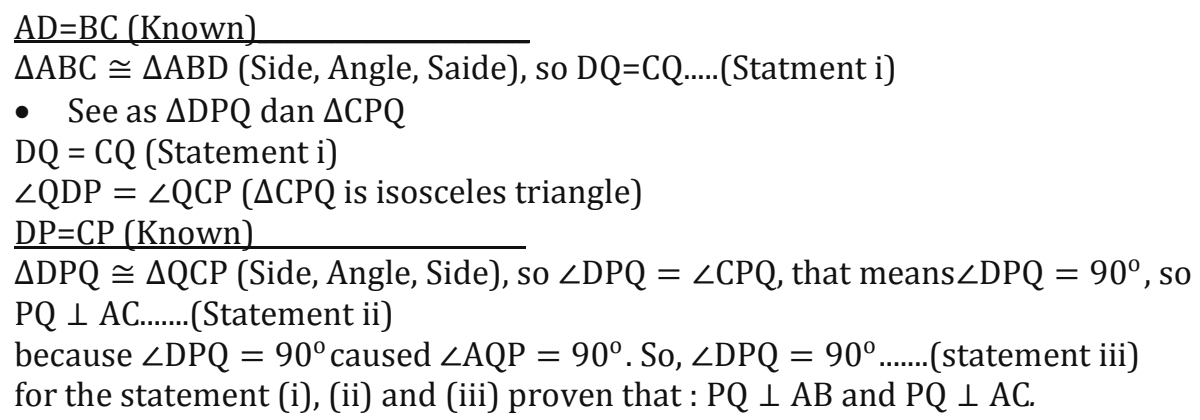

Student worksheets greatly assist students in understanding geometric proof. The practice exercises contained in the worksheet provide experiences for students in practicing geometric proof problems. For example, students are asked to write explanations of the evidentiary strategy by drawing sketches of images, writing information that is known to write the interrelationships of the theorems used, and writing formal proof (See Figure 2).

The self-explanation strategy is a star inference to anticipate reasoning. The anticipation of reasoning can predict the follow-up and coherence of the problem to be proven. In learning of self-explanation strategy, students enable expressing their thoughts, so that strategy ideas in solving proof problems. Based on the interview results, students felt helped by the help questions on the student worksheet. So, through self-explanation strategies, students can develop questions that will create ideas and ideas for evidence. In addition, with self-explanation strategies, students are able to explain to themselves and the group of geometric proof that has been constructed. The results of the interview with students (R1, R2, R3) are the following:

$P \quad: \quad$ Related to self-explanation, in student worksheets, there are questions that help selfexplanation, what do you think about these questions, are they helpful in the learning process?

$R 1$ : Actually those questions are helpful [nod]..because those questions help to obtain a conclusion

$P \quad$ : In the self-explanation process, explaining to ourselves, we usually mumble when solving problems [paused for a moment because the conversation was cut off by respondent]

$R 1$ : Yes, I mumbled [cut off the question]

$P \quad$ : Why you did it, R1? [mentioning the name of respondent]

R1 : Firstly, usually, when we say something by words, we will memorize instead of we scribe and mutter in our hearts. Probably it will be remembered faster if we mumble

$P \quad$ : When explaining something in a group, which one is more comfortable, explaining directly or explaining while giving scribbles?

$R 1$ : Yes sir, why if we often explain or are explained, we can absorb knowledge easily from the material?

$P \quad$ : Well, next question, in self-explanation learning, how is the importance of the selfexplanation process? What do you think, R2?

R2 : It is very important because that is not only to add knowledge to ourselves but also to others. So, if we understand the material, we can explain and be more fluent.

$P \quad$ : Related to self-explanation, when we face problems, we will think something, what R3 [mentioning the name of respondent] do when you are facing problems?

R3 : My strategy is to identify the problem carefully, then read the previous material. If there is an obstacle, I will ask my friend.

$P \quad$ : What questions are usually come up in your mind?

R3 : How to draw a sketch

$P \quad:$ and then?

R3 : Connecting to suitable theorems 
According to the interview results, R1 revealed that self-explanation was very helpful. R1 muttered when solving a proof problem. Muttering activity is meant to explain the answer. According to R1, when expressed an answer by words, it would be better than muttering in the heart. Thus, when solving problems of questions in our minds, it was done by muttering so that the knowledge gained would be easier to remember. Furthermore, R1 also wrote the answers in front of his/her group member while explaining the answers. For $\mathrm{R} 1$, this way was easier to remember and understand the discussed material.

Meanwhile, R2 revealed that self-explanation is very important because it is not only adding knowledge to our selves but also to others by explaining. According to R1, when we often explain, we will absorb the explained material easily. In line with R2, R3 also revealed the importance of self-explanation. When facing proof, R3 tried to think of something and ask themselves how to solve it, represent the sketch of the picture, and what suitable theorems are. Thus, a self-explanation process which is helped by guided questions in worksheets of student can help students in solving and understanding geometry proof problems. This is consistent with the results of research conducted by Azrou and Khelladi (2019), which revealed that in the process of proof scaffolding in the form of questions is very helpful for students to express the argument of proof and develop it in the form of statements that point to the proof intended.

The description above shows that the self-explanation strategy is effective in improving the ability to understand the geometric proof. The learning process using selfexplanation strategies emphasizes the active role of students in addressing the problems provided in the sheet. They are presented with guided questions to help students draw conclusions. The results showed that there was no interaction between self-explanation strategy and initial mathematical abilities, which meant that the self-explanation strategy was effective for all levels of students' initial mathematical abilities. This shows that there is an opportunity to apply a self-explanation strategy in developing the ability to understand proof for other material, outside of geometry.

\section{Conclusion}

The self-explanation strategy is effective learning in supporting the process of understanding geometric proof for students. This research concludes: first, the increased ability to understand the geometric proof of students who used self-explanation strategy was better than those who used direct learning; second, there was a difference in the ability to increase the understanding of geometric proof in terms of the level of initial mathematical ability (high, medium, low); and third, there was no interaction effect of learning factors and initial mathematical ability on increasing the ability to understand the geometric proof. It shows that the initial ability of mathematics does not directly affect the learning process to improve the ability to understand the geometric proof. Hence, the selfexplanation strategy was very effective for all initial mathematical ability. To sum up, the self-explanation strategy is effective for improving the ability to understand the geometric proof, especially for students who have high and medium mathematical initial abilities.

The self-explanation is an alternative learning strategy in geometry, particularly in higher education. Activities in the learning process using self-explanation enable students to complete their provided analysis assignments to develop students' understanding of the geometric proof. Therefore, the researcher recommends further research to focus on developing worksheets based on structured self-explanation questions and the difficulty level of geometry material. It is crucial because it determines the successful implementation of the self-explanation strategy. 


\section{Acknowledgement}

Thank you to students of mathematics education department in one of the private universities in Semarang who participated in this research.

\section{Bibliography}

Ainsworth, S., \& Burcham, S. (2007). The impact of text coherence on learning by selfexplanation. Learning and Instruction, 17(3), 286-303. https://doi.org/10.1016/j.learninstruc.2007.02.004

Al Rumayyan, A., Ahmed, N., Al Subait, R., Al Ghamdi, G., Mohammed Mahzari, M., Awad Mohamed, T., ... Schmidt, H. G. (2018). Teaching clinical reasoning through hypothetico-deduction is (slightly) better than self-explanation in tutorial groups: An experimental study. Perspectives on Medical Education, 7(2), 93-99. https://doi.org/10.1007/s40037-018-0409-x

Arnawa, I. M., Sumarno, U., Kartasasmita, B., \&Baskoro, E. T. (2007). Applying the Apos Theory To Improve Students Ability To Prove in Elementary Abstract Algebra. Journal of the Indonesian Mathematical Society, 13(1), 133-148. https://doi.org/10.22342/jims.13.1.80.133-148

Azrou, N., \& Khelladi, A. (2019). Why do students write poor proof texts? A case study on undergraduates' proof writing. Educational Studies in Mathematics, 102(2), 257 274. https://doi.org/10.1007/s10649-019-09911-9

Bieda, K. N., Ji, X., Drwencke, J., \& Picard, A. (2014). Reasoning-and-proving opportunities in elementary mathematics textbooks. International Journal of Educational Research, 64, 71-80. https://doi.org/10.1016/j.ijer.2013.06.005

Chi, M. T. H., De Leeuw, N., Chiu, M. H., \&Lavancher, C. (1994). Eliciting self-explanations improves understanding. Cognitive Science, 18(3), 439-477. https://doi.org/10.1016/0364-0213(94)90016-7

Conati, C. (2016). Commentary on: "toward Computer-Based Support of MetaCognitive Skills: A Computational Framework to Coach Self Explanation." International Journal of Artificial Intelligence in Education, 26(1), 183-192. https://doi.org/10.1007/s40593-015-0074-8

Fiallo, J., \& Gutiérrez, A. (2017). Analysis of the cognitive unity or rupture between conjecture and proof when learning to prove on a grade 10 trigonometry course. Educational Studies in Mathematics, 96(2), 145-167. https://doi.org/10.1007/s10649-017-9755-6

Haeruman, L. D., Rahayu, W., \& Ambarwati, L. (2017). Pengaruh Model Discovery Learning Terhadap Peningkatan Kemampuan Berpikir Kritis Matematis dan Self-Confidence Ditinjau dari Kemampuan Awal Matematis Siswa SMA di Bogor Timur. Jurnal Penelitian Dan Pembelajaran Matematika, 10(2), 157-168. https://doi.org/10.30870/jppm.v10i2.2040

Hodds, M., Alcock, L., \& Inglis Loughborough, M. (2014). Self-explanation training improves proof comprehension. Journal for Research in Mathematics Education, 45(1), 62-101. 
https://doi.org/10.5951/jresematheduc.45.1.0062

Kumar, A. N. (2014). An evaluation of self-explanation in a programming tutor. Lecture Notes in Computer Science (Including Subseries Lecture Notes in Artificial Intelligence and Lecture Notes in Bioinformatics), 8474 LNCS, 248-253. https://doi.org/10.1007/978-3-319-07221-0 30

Kurby, C., Magliano, J., Dandotkar, S., Woehrle, J., Gilliam, S., \& McNamara, D. (2012). Changing how students process and comprehend texts with computer-based selfexplanation training. Journal of Educational Computing Research, 47(4), 429-459. https://doi.org/10.2190/EC.47.4.e

Kwon, K., Kumalasari, C. D., \& Howland, J. L. (2011). Self-explanation prompts on problemsolving performance in an interactive learning environment. Journal of Interactive Online Learning, 10(2), 96-112.

Lestari, W. (2017). Pengaruh Kemampuan Awal Matematika dan Motivasi Belajar terhadap Hasil Belajar Matematika. Jurnal Analisa, 3(1), 76. https://doi.org/10.15575/ja.v3i1.1499

Maarif, S, Perbowo, K. S., Noto, M. S., \& Harisman, Y. (2019). Obstacles in Constructing Geometrical Proofs of Mathematics-Teacher-Students Based on Boero's Proving Model. Journal of Physics: Conference Series, 1315, 012043. https://doi.org/10.1088/1742-6596/1315/1/012043

Maarif, S. (2013). Aplikasi Software Cabri Geometri Pada Materi GeometriSebagai Upaya Mengeksplorasi Kemampauan Matematis. Prosiding Seminar Nasional Matematika Dan Pendidikan Matematika STKIP Siliwangi, Bandung. Vol. 1, pp. 261-271.

Maarif, S, Wahyudin, W., Noto, M. S., Hidayat, W., \&Mulyono, H. (2018). Geometry Exploration Activities Assisted With Dynamic Geometry Software (Dgs) in a Teacher $\begin{array}{lllll}\text { Education Classroom. Infinity Journal, } & 7(2),\end{array}$ https://doi.org/10.22460/infinity.v7i2.p133-146

McNamara, D. S. (2017). Self-Explanation and Reading Strategy Training (SERT) Improves Low-Knowledge Students' Science Course Performance. Discourse Processes, 54(7), 479-492. https://doi.org/10.1080/0163853X.2015.1101328

Nguyen, N. T., Trawiński, B., \& Kosala, R. (2015). Intelligent information and database systems 7th asian conference, ACIIDS 2015 Bali, Indonesia, march 23-25, 2015 roceedings, part II. Lecture Notes in Computer Science (Including Subseries Lecture Notes in Artificial Intelligence and Lecture Notes in Bioinformatics), 9012, 1-2. https://doi.org/10.1007/978-3-319-15705-4

Otten, S., Gilbertson, N. J., Males, L. M., \& Clark, D. L. (2014). The Mathematical Nature of Reasoning-and-Proving Opportunities in Geometry Textbooks. Mathematical Thinking and Learning, 16(1), 51-79. https://doi.org/10.1080/10986065.2014.857802

Reiss, K., \&Renkl, A. (2002). Learning to prove: The idea of heuristic examples. ZDM International Journal on Mathematics Education, 34(1), 29-35. https://doi.org/10.1007/BF02655690

Rittle-Johnson, B., Loehr, A. M., \& Durkin, K. (2017). Promoting self-explanation to improve 
mathematics learning: A meta-analysis and instructional design principles. ZDM Mathematics Education, 49(4), 599-611. https://doi.org/10.1007/s11858-017-0834$\underline{\mathrm{Z}}$

Roy, M. \& Chi, M. T. . (2005). The Self-explanation Principle. Cambridge Handbook of Multimedia Learning, (0325054), 271-286. Retrieved from http://chilab.asu.edu/papers/MultiM chapter final.pdf

Samper, C., Perry, P., Camargo, L., Sáenz-Ludlow, A., \& Molina, Ó. (2016). A dilemma that underlies an existence proof in geometry. Educational Studies in Mathematics, 93(1), 35-50. https://doi.org/10.1007/s10649-016-9683-x

Sommerhoff, D., \&Ufer, S. (2019). Acceptance criteria for validating mathematical proofs used by school students, university students, and mathematicians in the context of teaching. ZDM - Mathematics Education, O(0), 0. https://doi.org/10.1007/s11858019-01039-7

Sztajn, P., Wilson, H., Edgington, C., Myers, M., \& Dick, L. (2013). Using Design Experiments to Conduct Research on Mathematics Professional Development. Alexandria: Revista de EducaçãoEmCiência e Tecnologia, 6(1), 9-34. https://doi.org/10.5007/\%x

Tekeng, N. Y. (2015). Using self-explanation strategy to improve students' understanding of the to be learned material. Auladuna, 2(36), 173-184.

Tsitouras, A., Tsivilis, S., \&Kakali, G. (2014). A Taguchi Approach for the Synthesis Optimization of Metakaolin Based Geopolymers. In Advances in Science and Technology (Vol. 92). https://doi.org/10.4028/www.scientific.net/ast.92.44

Vilkomir, T., \&O’Donoghue, J. (2009). Using components of mathematical ability for initial development and identification of mathematically promising students. International Journal of Mathematical Education in Science and Technology, 40(2), 183-199. https://doi.org/10.1080/00207390802276200

Wylie, R., Koedinger, K. R., \& Teruko, M. (2004). Is Self-Explanation Always Better? The Effects of Adding Self-Explanation Prompts to an English Grammar Tutor Adding SelfExplanation to an Existing Tutor. Human-Computer Interaction, (Figure 1), 13001305.

Yu, Z., Ding, Y. L., Lu, F., Miao, L. Y., Shen, Z. Y., \& Ye, W. X. (2015). Warfarin dosage adjustment strategy in Chinese population. International Journal of Clinical and Experimental Medicine, 8(6), 9904-9910. 